\title{
Tocopherol induced angiogenesis in placental vascular network in late pregnant ewes
}

\author{
Ramanathan K Kasimanickam ${ }^{1 *}$, Vanmathy R Kasimanickam, Jacobo S Rodriguez ${ }^{1}$, Kevin D Pelzer², \\ Philip D Sponenberg ${ }^{2}$, Craig D Thatcher ${ }^{3}$
}

\begin{abstract}
Background: Tocopherols have biphasic, proangiogenic and antiangiogenic therapeutic effects. The objective of this clinical trial was to clarify tocopherol's placental angiogenic potential in late pregnant ewes following oral supplementation.

Methods: Eighteen pregnant ewes during late gestation were selected for this study. Ewes were given oral supplementation of $500 \mathrm{mg}$ of alpha-tocopherol ( $\mathrm{aT} ; \mathrm{N}=6)$ or $1000 \mathrm{mg}$ of gamma-tocopherol ( $\mathrm{gT} ; \mathrm{N}=7$ ) or placebo (CON; $N=5$ ) once daily from 107 to 137 days post breeding. Serum was obtained at weekly intervals and tissue samples were obtained at the end of supplementation to: 1) evaluate tocopherol concentrations in serum, uterus and placentome; 2) evaluate relative mRNA expressions of Vascular Endothelial Growth Factor (VEGF), Placental Growth Factor (PIGF), endothelial Nitric Oxide Synthase (eNOS) and Hypoxia Inducible Factors (HIF) in uterus, caruncle and cotyledon; 3) analyze the morphometry of the placental vascular network.

Results: Supplementation of aT or gT resulted in increased concentrations in serum, placentome and uterus compared to control $(P<0.05)$. In aT group, mRNA expressions of PIGF, eNOS and HIF-1 $\alpha$ in cotyledon were greater than the CON group. In gT group, mRNA expressions of VEGF, eNOS, HIF-1 alpha and HIF-2 alpha in caruncle and uterus, and HIF- $1 \alpha$ in cotyledon, were greater than the CON group. Morphometry analysis revealed increased angiogenesis in the supplemented groups.
\end{abstract}

Conclusion: Daily oral supplementation of aT or gT increased angiogenesis in the placental vascular network in pregnant ewes during late gestation. Increase in placental angiogenesis may provide nutrients required for the development and growth of fetus during late pregnancy.

\section{Background}

Angiogenesis is the process of development of new blood vessels from an existing vascular network [1]. Hypoxia constitutes a basic regulatory mechanism in vascular development during embryonic and fetal growth in utero [2]. In endothelial cells, hypoxic conditions drive the transcription of multiple genes which control vascular function, expansion and remodeling. Although tissue hypoxia is the main driving force for angiogenesis, a growing body of evidence has demonstrated that oxidative stress can also be a potent trigger for the development of new vessels [3-6].

\footnotetext{
* Correspondence: ramkasi@vetmed.wsu.edu
'College of Veterinary Medicine, Washington State University, Pullman, WA

* Correspondence: ramkasi@vetmed.wsu.edu 99164, USA
} 99164, USA

\section{()

Two families of radicals, reactive oxygen species (ROS) and reactive nitrogen species (RNS) are very crucial to growth, differentiation, apoptosis, and aging. The transition from growth to degeneration of cells is finely tuned by the relative concentration of oxidants. For instance, in ambient conditions, $\mathrm{H}_{2} \mathrm{O}_{2}$ in nano-micromolar concentrations are necessary for angiogenesis [7], while its excessive accumulation at levels more than $150-200 \mu \mathrm{M}$ prompts endothelial damage [8]. An imbalance of free radicals attacks and alters cell constituents, resulting in lipid peroxidation, protein peroxidation, oxidative inactivation, mutation of DNA, and destruction of vitamins and other functions that protect cell components [9]. Excessive accumulation of free radicals affects placental development and function, and may subsequently impact both the fetus and dam [10-13]. The dietary antioxidants are important in attenuating the oxidative 
damage produced by radicals $[13,14]$. Tocopherols are micronutrients which act as free radical scavengers. The major tocopherols found in mammalian tissue are alpha-tocopherol (aT) and gamma-tocopherol (gT). Studies on tocopherol in humans have shown that aT constitutes 80 to $90 \%$ of vitamin $\mathrm{E}$ in plasma, which is due to the preferential incorporation of aT into very lowdensity lipoprotein via tocopherol-binding protein, and a rapid catabolism of gT within the liver [14]. Consequently, aT has received the most attention and is the primary form of vitamin $\mathrm{E}$ in supplements. However a recent work has suggested that under specific circumstances gT might scavenge reactive species more effectively than aT thereby, being more beneficial $[15,16]$. Gamma tocopherol affords higher protection against lipid peroxidation as compared to a $\mathrm{T}$ [17]. It has been demonstrated that high levels of aT intake can decrease gT [17]. Also gT has synergistic effect with other tocopherols and suggested as most promising agent to use. Hence we decided to use both tocopherols in this study. Human and animal studies have demonstrated that chronic supplementations with tocopherols have biphasic, proangiogenic and antiangiogenic therapeutic effects [18-22]. A recent study also concluded that tocoretinols not tocopherols suppressed Vascular Endothelial Growth Factor (VEGF) induced angiogenesis [23].

Optimal placental development is critical for fetal development and growth. Normal fetal growth is genetically pre-programmed and regulated by fetal, placental, maternal and environmental factors. A range of pathophysiological factors including maternal stress due to poor nutrition, hyperthermia or metabolic diseases such as pregnancy toxemia and eclampsia may affect important metabolic, transport and hemodynamic functions of placentas. This may lead to fetal stress due to poor supply of nutrition and thus impairment in fetal growth. A recent study demonstrated that glucocorticoid induced restriction of fetal and placental growth is mediated through reduced placental expression of VEGF and associated reduction in placental vascualrization during late pregnancy [24]. Supplementation of antioxidants may negate oxidative stress, promote angiogenesis and increase nutrient supply to the fetus. The differential expression of VEGF and placental growth factors (PIGF) throughout gestation indicates that they both play essential roles in placental angiogenesis. Hypoxia inducible factor (HIF) $-1 \alpha$ or HIF- $2 \alpha$ combine with HIF- $1 \beta$ to form the functional basic helix-loop-helix transcription factor HIF-1 to stimulate transcription of the VEGF gene via interaction with the hypoxia response element (HRE) [25]. Several genes encoding growth factors and tyrosine kinase receptors essential for endothelial cell growth and function such as erythropoietin (EPO), VEGF, endothelial Nitric Oxide Synthase (eNOS) and
Flk-1 were shown to contain HIF-binding sites in their promoter/enhancer sequences.

We hypothesize that oral supplementation of tocopherols during late gestation in ewes will increase tocopherol levels in the circulation, resulting in increased concentrations in the uterus and placenta and thereby increasing the expression of angiogenic genes and exerting an angiogenic effect. The objectives of the study were to: 1) compare aT and gT concentrations in serum, uterine and placentomal tissues among supplemented and CON groups; 2) compare angiogenic gene (VEGF, PlGF, eNOS, and HIFs) expressions in the uterus, caruncle and cotyledon among supplemented and CON groups; and 3) compare angiogenic morphometric parameters of the uteroplacental vascular network of late pregnant ewes supplemented with aT, gT, or placebo.

\section{Methods}

Eighteen pregnant ewes ( 2 to 6 years of age and weighing approximately $68 \mathrm{~kg}$; impregnated by different sires by natural service), with similar breeding dates were selected for the current study and were mainatined under normal pasture conditions. One week prior to the trial, the selected ewes were moved to the research facility and were penned by treatment groups. The ewes had access to $35 \mathrm{sq} \mathrm{ft} /$ ewe paddock lots. In addtion they were fed $250 \mathrm{~g}$ of concentrate/ewe/day and free choice hay. The composition of hay is given in Additional file 1, Table S1. This study was approved by Virginia Tech institutional animal care and use committee (IACUC; 04-068-CVM). Tissue Use Protocol was approved by IACUC at Washington State University (ASAF \#03922001).

The ewes were randomly assigned to three groups: 1 ) aT group $(\mathrm{n}=6)$ - received $500 \mathrm{mg}$ of aT (Nature's Bounty, Bohemia, NY 11716), 2) gT group ( $=7$ ) received $1000 \mathrm{mg}$ of gT (Kemin Industries Inc., Des Moines, Iowa 50317), 3) Control (CON) group $(n=5)$ received a placebo. The average tocopherols concentrations in the supplement is given in Additional file 2, Table S2. Animals were supplemented orally, once daily, from approximately 100 to 137 days post breeding (dpb) (Figure 1). Blood samples were collected one week prior to onset of supplementation and then weekly until the end of the supplementation period [ $94 \mathrm{dpb}$ (presupplement level), $107 \mathrm{dpb}, 114 \mathrm{dpb}, 121 \mathrm{dpb}, 128 \mathrm{dpb}, 136 \pm$ $1 \mathrm{dpb}$ ] for serum aT and gT evaluation (Figure 1). At the end of the supplementation period (136 \pm 1 ), all ewes were euthanized and tissue samples were collected from the gravid uterus and placentomes to evaluate aT and gT concentrations. Tissue samples were snap frozen and stored at $-70^{\circ} \mathrm{C}$ until analysis. Caruncle, cotyledon and intercaruncular uterus samples were also collected 


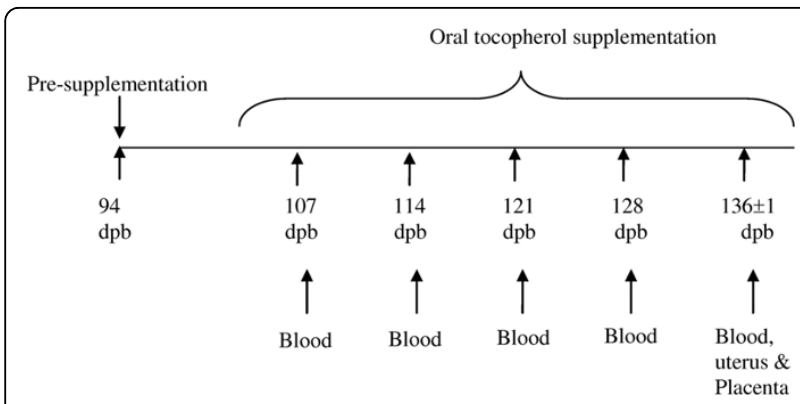

Figure 1 Schematic representation of treatment regimen and sample collection. dpb - days post breeding.

and stored in RNAlater (Qiagen Inc., Valencia, CA 91355) and frozen at $-70^{\circ} \mathrm{C}$ to evaluate mRNA expression. Cotyledones were separated from caruncles by applying strong pressure. Placentomal and uterine tissues were collected close to the umbilical cord for consistency.

\section{Serum tocopherol estimation}

The High Performance Liquid Chromatography (HPLC) method described by Panfili et al (2003) was employed for the quantification of tocopherols [26]. For each sample, dose-dependent $(10,50,100,500$ and $1000 \mathrm{mg} / \mathrm{L})$ tocopherols (Sigma-Aldrich, St. Louis, MO 63103) positive control were prepared. In a glass tube, $1 \mathrm{~mL}$ of serum sample and $20 \mu \mathrm{L}$ of aT acetate $(1000 \mathrm{mg} / \mathrm{L})$ in ethanol (internal standard to estimate yield of extraction) was added and vortexed. To this $1 \mathrm{ml}$ of ethanol containing $0.01 \%$ of butylated hydroxytoluene (BHT) was added. The tocopherols were extracted 3 times with $1 \mathrm{ml}$ of cyclohexane containing $0.01 \%$ BHT. After evaporation of the pooled cyclohexane fractions under a stream of nitrogen, the residues were reconstituted in $200 \mu \mathrm{L}$ of cyclohexane. The samples were filtered through a Pall Gellman Acrodisc ${ }^{\bullet}(0.2 \mu \mathrm{m} / 13 \mathrm{~mm})$ into a HPLC vial and subjected to a HPLC analysis to quantify the tocopherol's concentration.

\section{Uterine and placentomal tissue tocopherol estimation}

The HPLC method described by Katsanidis and Addis (1999) was employed for quantification of tocopherol concentrations in uterus and placentome samples [27]. Each uterine and placentomal tissue sample was homogenized separately in water $(1: 2)$ containing ascorbic acid $(62.5 \mathrm{~g}$ of ascorbic acid in $250 \mathrm{~mL}$ of double distilled water) to protect tocopherol from air oxidation during saponification process [27]. The tissue homogenates were aliquoted and frozen and stored at $-70^{\circ} \mathrm{C}$ until analysis. One point five grams of uterus or placental homogenate was placed in a screw cap tube and $0.125 \mathrm{~g}$ of ascorbic acid and $3.5 \mathrm{~mL}$ of the saponification solution $[55 \%$ ethanol in distilled water and $11 \% \mathrm{KOH}$ $(\mathrm{w} / \mathrm{v})]$ were added to the tissue. The tube with sample was heated to $80^{\circ} \mathrm{C}$ for $15 \mathrm{~min}$. After saponification, the tubes were cooled under tap water for $1 \mathrm{~min}$, and then $1 \mathrm{~mL}$ of distilled water was added. The solutions were extracted 3 times with $1 \mathrm{~mL}$ of cyclohexane containing $0.01 \%$ of BHT. The 3 extracts were combined and the solvent was evaporated under reduced pressure by a rotovap. The residue was reconstituted in $500 \mathrm{~mL}$ of ethanol containing $0.01 \%$ BHT.

An Agilent Technologies 1100 series liquid chromatography system (Agilent Technologies Inc. Santa Clara, CA 95051, USA) was used to perform HPLC analysis to quantify tocopherols in supplement, serum, and tissue samples. The analysis was conducted in normal phase, with a HPLC column Agilent Technologies Zorbax RxSi $150 \times 4.6 \mathrm{~mm}, 5 \mu$ with an elution solvent constituted of hexane-isopropanol $(99.7: 0.3)$ with a flow rate of $1 \mathrm{~mL} / \mathrm{min}$ and an injection volume of $10 \mu \mathrm{L}$. The tocopherols were analyzed by fluorescence with an excitation wavelength of $295 \mathrm{~nm}$ and emission wavelength of $330 \mathrm{~nm}$.

\section{Real Time Polymerase Chain Reaction}

Total RNA was extracted with RNeasy Mini Kit (QIAGEN Inc. Valencia, CA, USA) according to the manufacturer's protocol from uterine and placental tissues. Total RNA $(1 \mu \mathrm{g})$ was reverse transcribed into cDNA with a SuperScript II reverse transcriptase (Invitrogen, Carlsbad, CA 92008, USA) using random hexamers as a primer. Primers for the genes examined are listed in Table 1. To ensure the amplification of a single amplicon of the expected size, the product was viewed on an ethidium bromide stained electrophoresis gel. The RTPCR analyses for VEGF, PlGF, eNOS, HIFs and $18 \mathrm{~S}$ rRNA were performed using the ABI 7300 Sequence Detection System instrument and software (PE Applied Biosystems Inc., Foster City, CA, USA). To compare mRNA expression levels among samples, mRNA for each gene of interest was normalized to the expression of a housekeeping gene, $18 \mathrm{~s}$ RNA, and differences in gene expression were calculated as a fold change to the mean of the vehicle group using the $2^{-\Delta \Delta C t}$ method $[28,29]$.

\section{Morphometry analysis}

The placentome samples collected for histological evaluation were fixed in $10 \%$ neutral buffered formalin, sectioned at 5 microns, and stained with hematoxylin and eosin. They were evaluated on a Nikon E400 Eclipse microscope, and photomicrographs $(100 \times)$ were taken with a Nikon camera with a 3 chip. Images were processed with Nikon Act 1 software. Image processing and morphometry analysis were performed using ImageJ $1.42 \mathrm{q}(\mathrm{NIH}, \mathrm{USA})$ to evaluate the fractal dimension and 
Table 1 Primer sequences for Vascular Endothelial Growth Factor, Placental Growth factor, endothelial Nitric oxide Synthase and Hypoxia Inducible Factors

\begin{tabular}{|c|c|c|c|}
\hline Gene & Primer & Sequence $5^{\prime}$ to $3^{\prime}$ & GenBank accession number \\
\hline \multirow[t]{2}{*}{ VEGF } & Forward & TGTAATGACGAAAGTCTGGAG & AF071015 \\
\hline & Reverse & TCACCGCCTCGGCTTGTCACA & \\
\hline \multirow[t]{2}{*}{ PIGF } & Forward & TGCCGGTCATGAGGCTGT & NM_002632* \\
\hline & Reverse & GCAGTCACTGAAGAGTGTGAC & \\
\hline \multirow[t]{2}{*}{ eNOS } & Forward & TGGGCCGCATCCAGTG & NM_001129901 \\
\hline & Reverse & GAACATCTCCTGTGCTGAGCTG & \\
\hline \multirow[t]{2}{*}{$\mathrm{HIF}-1 \alpha$} & Forward & TCAGCTATTTGCTGTGAGG & EU340260 \\
\hline & Reverse & TTCACAAATCAGCACCAAGC & \\
\hline \multirow[t]{2}{*}{ HIF-1 $\beta$} & Forward & AGA TGC AGG AAT GGA CTT GG & EU340261 \\
\hline & Reverse & CCT GGC CTT TTA ACT TCA CG & \\
\hline \multirow[t]{2}{*}{ HIF-2 $\alpha$} & Forward & AAGTCAGCCACCTGGAAGG & EU340264 \\
\hline & Reverse & TCACACACATCATGCACTGG & \\
\hline \multirow[t]{2}{*}{ HIF- $2 \beta$} & Forward & AGGATGAGGTGTGGAAATGC & EU340265 \\
\hline & Reverse & CCTCAGAGTGGCAGAACTCC & \\
\hline
\end{tabular}

*Homology to human

lacunarity [30,31]. The main processing steps applied to the images are shown in Figure 2. Briefly, after downloading the original image in the software, they were converted to 8 bit black and white images, and thresholding was performed by selecting mean value as threshold value. The images were made binary and were skeletonized.
Fractal analysis is a contemporary method of applying nontraditional mathematics to patterns that defy understanding with traditional Euclidean concepts. Fractal analysis measures complexity using the fractal dimension. A fractal dimension is, in essence, a scaling rule comparing how a pattern's detail changes with the scale at which it is considered. The fractal dimension is a

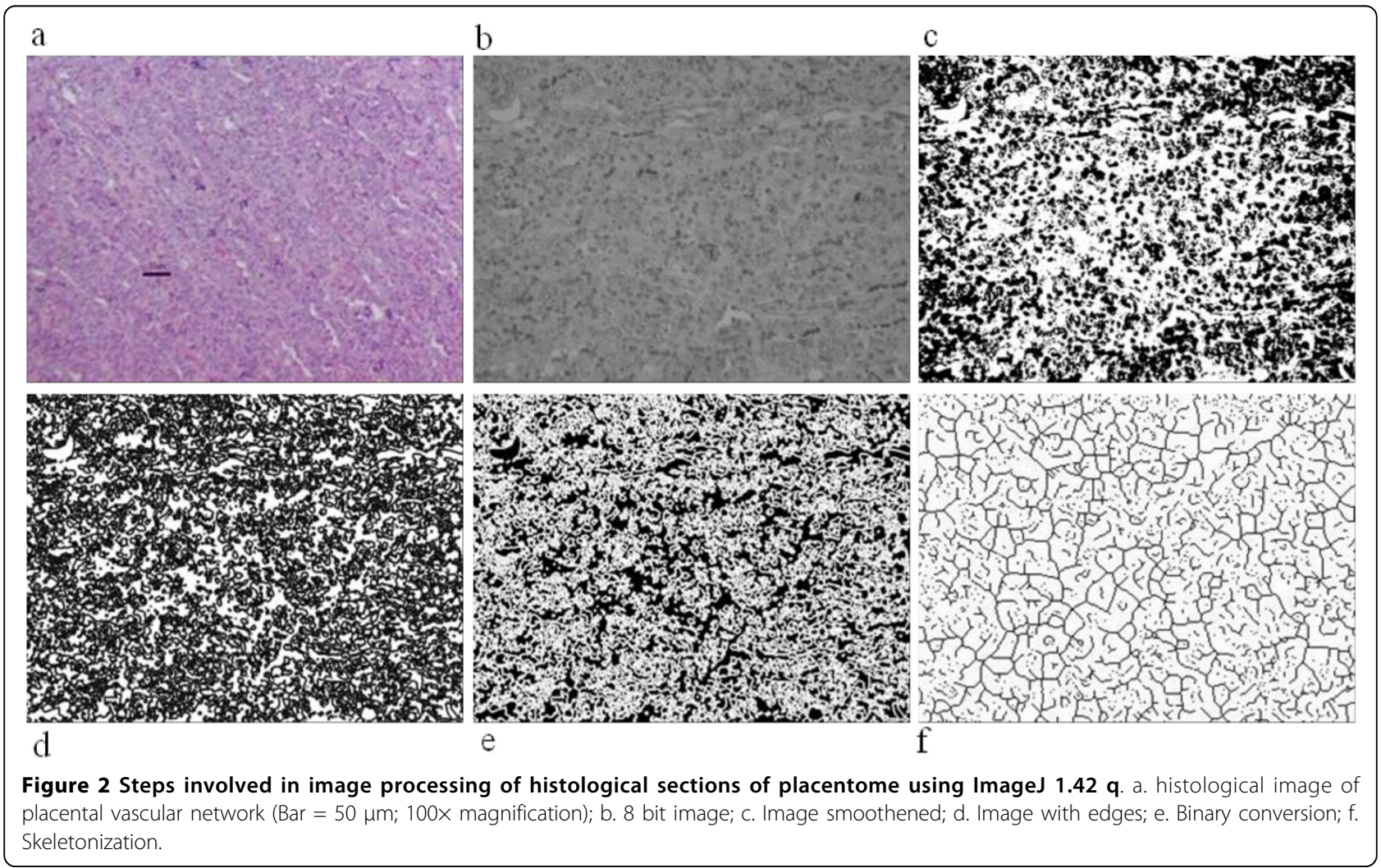


valuable parameter to describe the complexity. FarcLac 2.5 release $1 \mathrm{~b} 5 \mathrm{~m}$ (NIH, USA) was used to perform fractal dimension. The FracLac scan images using a shifting grid algorithm that can do multiple scans from different locations on each image. The fractal dimension of the binary skeleton was estimated using the box counting method at multiple origins. The basic procedure is to systematically lay a series of grids of decreasing calibre (the boxes) over an image and record data (the counting) for each successive calibre. To minimize grid location effects, the algorithm started from number of locations, generating a set of variables for fractal dimension. The average value over all locations was considered as the final estimate of fractal dimension. During the same analytical process 'Lacunarity" was also calculated. This parameter is a measure of homogeneity of structure or the degree of structural variance within an object. It was estimated as the average of the coefficient of variation for pixel density over all grid sizes and locations. The field demarked as a square in Figure 3 is one location. A total of 30 locations were evaluated for each sample.

\section{Statistical analyses}

The MIXED procedure of the SAS System (SAS version 9.12, SAS Institute Inc., Cary, NC 27513) was used to perform a repeated measures analysis of covariance to test for effects of treatments (aT, gT and CON), days post breeding [94 dpb (pre-supplement level), $107 \mathrm{dpb}$, $114 \mathrm{dpb}, 121 \mathrm{dpb}, 128 \mathrm{dpb}), 136 \pm 1 \mathrm{dpb}$ ] and their interactions on the serum concentration of tocopherols. Covariation of repeated measurements was modeled as compound symmetric and model adequacy was assessed using plots of standardized residuals. The differences in the serum tocopherol concentrations between pre-supplement stage and post supplement stages of gestation were tested by creating contrast statements. Analysis of variance was used to determine the within treatment between days post breeding differences and within days post breeding between treatment differences. Since the data were not normally distributed, a non-parametric procedure was used to perform the Kruskal-Wallis method test to compare the median tocopherol concentrations in serum, placenta and uterus among the treatment groups (Table 2). For responses with significant differences, pair-wise comparisons were performed using Minitab 12.1 (Minitab Inc., State College, PA, USA).

The RT-PCR data were subjected to ANOVA using 2$\Delta \triangle \mathrm{Ct}$ values to ascertain statistical significance of any differences in VEGF, PIGF, eNOS and HIFs expression in placebo vs. tocopherol-treated groups [29]. The differences in fractal dimension and lacunarity among treatment groups were tested by non-parameteric KruskalWallis method. There were 3 ewes ( 2 in CON and 1 in

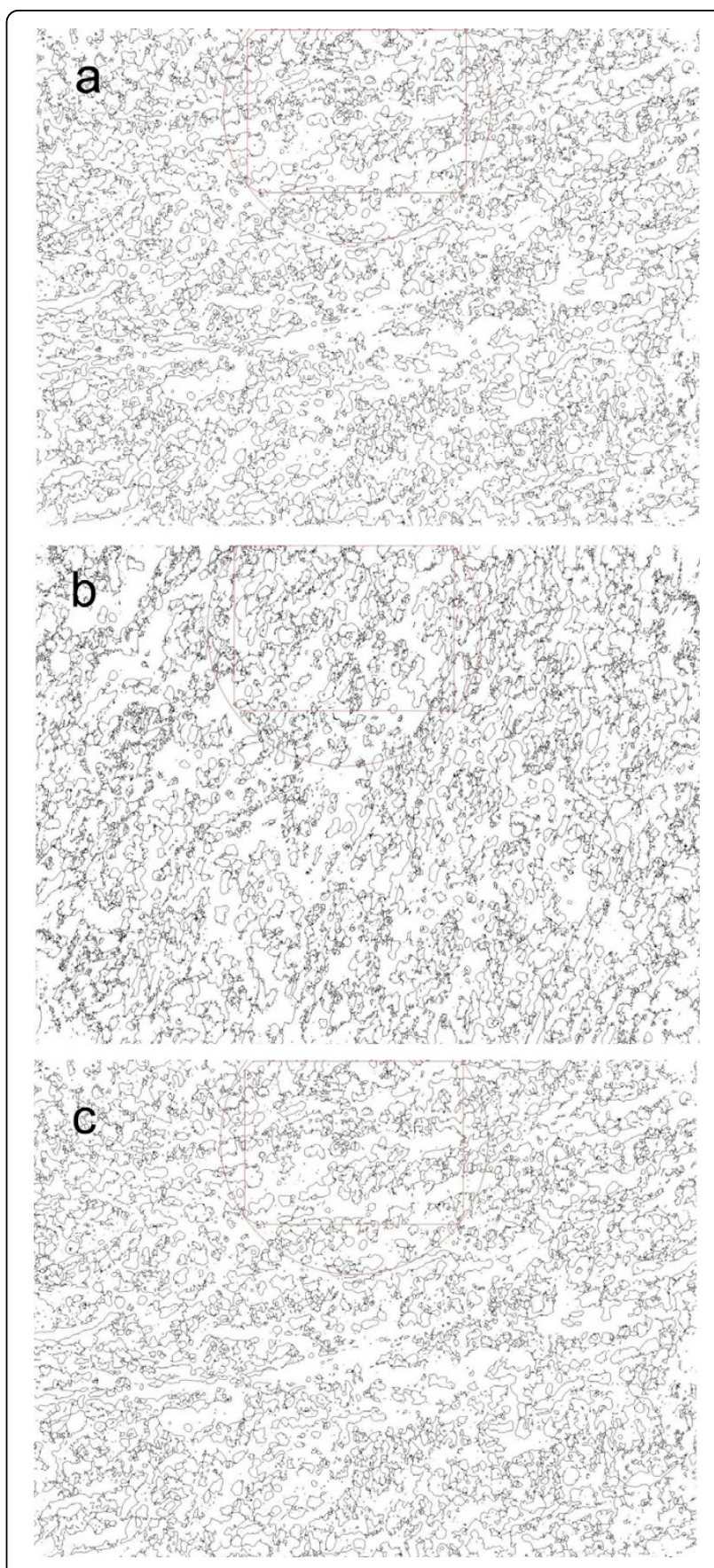

Figure 3 Morphometric analysis of placental vascular network of late pregnant ewes supplemented with alpha tocopherol, gamma tocopherol or placebo. a. Morphometric parameter of placental network of ewe supplemented with $\gamma$ tocopherol. Field demarked as red-square had Fractal dimension 1.6204 and lacunarity 0.4967 . A total of 30 fields were evaluated for each sample; b. Morphometric parameter of placental network of ewe supplemented with $\alpha$ tocopherol. Field demarked as red-square had Fractal dimension 1.7030 and lacunarity 0.5884 . A total of 30 fields were evaluated for each sample. c. Morphometric parameter of placental network of ewe treated with placebo. Field demarked as red-square had Fractal dimension 1.6263 and lacunarity 0.6033. A total of 30 locations were evaluated for each sample. 


\begin{tabular}{|c|c|c|c|}
\hline \multirow[b]{2}{*}{ Tissue } & \multirow[b]{2}{*}{ Treatment Groups } & \multicolumn{2}{|c|}{ Concentrations } \\
\hline & & aT $(\mathrm{mg} / \mathrm{kg})$ & $\mathrm{gT}(\mu \mathrm{g} / \mathrm{kg})$ \\
\hline \multirow[t]{3}{*}{ Placenta } & $\mathrm{aT}$ & $9.19(6.77,12.1)^{a}$ & $45.5(10.0,83.3)^{a}$ \\
\hline & gT & $2.74(2.26,6.22)^{b}$ & $607(477,1057)^{b}$ \\
\hline & Control & $2.88(1.85,4.16)^{b}$ & $92.4(57.6,153.0)^{a}$ \\
\hline \multirow[t]{3}{*}{ Uterus } & aT & $5.23(4.38,6.50)^{a}$ & $0(0,189.3)^{a}$ \\
\hline & gT & $3.28(2.34,3.54)^{b}$ & $737.7(607.1,979.6)^{b}$ \\
\hline & Control & $2.34(1.91,3.87)^{\mathrm{b}}$ & $156.5(110.3,237.1)^{c}$ \\
\hline
\end{tabular}

${ }^{\mathrm{abc}}$ different superscripts between treatment groups within tissue are significantly different $(\mathrm{P}<0.05)$; aT- alpha tocopherol; gT-gamma tocopherol; CON - Control

aT) that had twins. The the results did not change after inclusion, exclusion averaging the the values from twins; however excluded from the analysis.

\section{Results}

\section{Serum tocopherol concentrations}

Serum tocopherol concentrations were significantly different between treatment groups $(\mathrm{P}<0.0001)$ and days post breeding ( $\mathrm{P}<0.0001$; Additional file 3 , Table S3). Significant treatment $\times$ days post breeding interaction was observed ( $\mathrm{P}<0.0001$; Additional File 3, Table S3). The pre-supplementation serum levels of a $\mathrm{T}$ compared to post-supplemental stages of gestation were different between aT and gT groups $(\mathrm{P}<0.0001$; Additional file 4 , Table S4), and between aT and CON groups $(\mathrm{P}<$ 0.0001; Additional file 4, Table S4) and not between gT and CON groups ( $\mathrm{P}>0.05$; Additional file 4, Table S4). The pre-supplementation gT serum concentrations compared to other stages of gestation were different between gT and aT groups $(\mathrm{P}<0.0001$; Additional file 4, Table S4), and between $\mathrm{gT}$ and $\mathrm{CON}$ groups $(\mathrm{P}<0.0001 ;$ Additional file 4, Table S4) and not between aT and CON groups $(\mathrm{P}>0.05$ Additional file 4, Table S4).

Pair-wise comparisons of the median $\left(25^{\text {th }}, 75^{\text {th }}\right.$ percentile) serum aT concentrations (excluding pre-supplementation level) were significantly higher for ewes in aT group compared to ewes in gT and CON groups during the trial period for the respective stages $(\mathrm{P}<0.001$; Figure $4 \mathrm{a}$ and additional file 4, Table S4). Pair-wise comparison of median tocopherol levels between stages within treatment groups was different for the aT group $(\mathrm{P}<0.05)$ but not in $\mathrm{gT}$ and $\mathrm{CON}$ groups $(\mathrm{P}>0.05)$. Similarly, pair-wise comparisons of the median $\left(25^{\text {th }}\right.$, $75^{\text {th }}$ percentile) serum gT concentrations (excluding pre-supplementation level) were significantly higher for ewes in the gT group compared to ewes in aT and CON groups during the trial period for the respective stages (Figure $4 \mathrm{~b}$ and additional file 4, Table S4).
Pair-wise comparison of median tocopherol levels between stages within treatment groups was different for the gT group $(\mathrm{P}<0.05)$ but not in aT and $C O N$ groups $(\mathrm{P}>0.1)$.

\section{Uterine and placental tocopherol concentrations}

The median aT tocopherol concentration in placentome and uterus was greater in ewes supplemented with aT compared to ewes in $\mathrm{gT}$ and $\mathrm{CON}$ groups $(\mathrm{P}<0.05$; Table 2$)$. The median $\mathrm{gT}$ concentrations in placentome and uterus were greater in ewes supplemented with gT compared to ewes in the aT and CON groups $(\mathrm{P}<0.05$; Table 2$)$. The median $\mathrm{gT}$ in the uterus of $\mathrm{CON}$ ewes was greater than aT supplemented ewes $(\mathrm{P}<0.05$; Table 2$)$.

\section{Vascular Endothelial Growth Factor, Placental Growth Factor, endothelial Nitrous Oxide Synthase and Hypoxia Inducible Factors expression}

Figure 5a shows expression of VEGF, PIGF and eNOS in placenta and uterus in tocopherol supplemented groups relative to $\mathrm{CON}$, where control is 1 . In cotyledon, the PlGF and eNOS expression in ewes supplemented with aT was significantly higher compared to the CON group. The VEGF expression was not different between $\mathrm{aT}$ and the CON groups. The VEGF, PlGF and eNOS expressions in ewes supplemented with gT were not different from the CON group. In caruncle and uterus, the VEGF and eNOS expressions in ewes supplemented with gT were significantly higher compared to the CON group. The PlGF expression was not different between gT and the CON groups. The VEGF, PlGF and eNOS expressions in ewes supplemented with aT were not different from the CON group.

The hypoxia inducible factors gene expression in tocopherol supplemented ewes relative to CON (1.0 fold) are given in Figure $5 \mathrm{~b}$. Ewes that received aT showed an increase in HIF- $1 \alpha$ mRNA expression in cotyledon compared to control $(\mathrm{P}<0.05)$. In gT supplemented ewes, the mRNA expressions of HIF-1 $\alpha$ in cotyledon, and HIF- $1 \alpha$ and HIF- $2 \alpha$ in caruncle and uterus were higher compared to controls $(\mathrm{P}<0.05)$. There was no HIF-1 $\beta$ expression in cotyledon, caruncle and uterus.

\section{Morphometry analysis}

The results showed that a $\mathrm{T}$ or gT supplemented ewes had increased fractal dimension and decreased lacunarity in their placental vascular network compared to CON ewes (Figure 6; $\mathrm{P}<0.05$ ).

\section{Discussion}

The goal of this study was to investigate the differences in angiogenic potential of alpha- and gammatocopherol. We evaluated biweekly serum, and uterine 
a

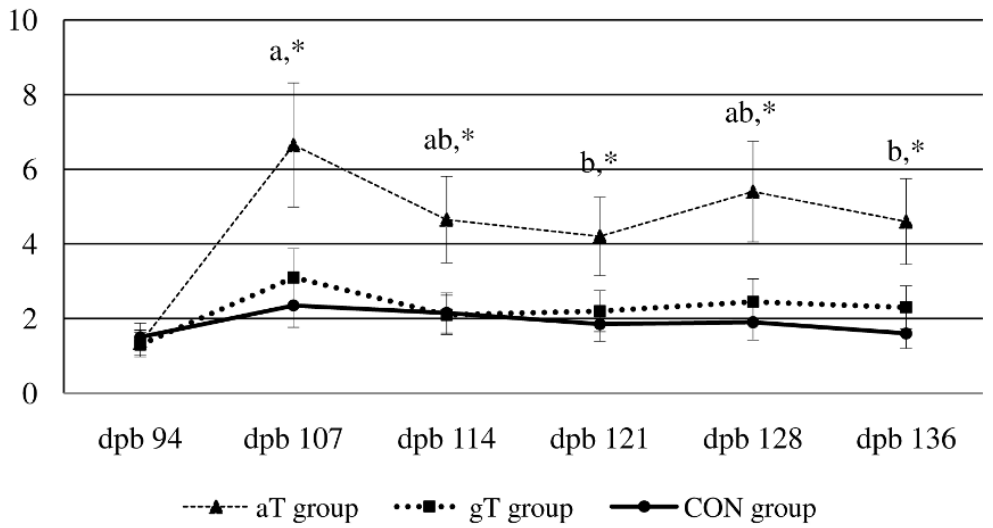

b

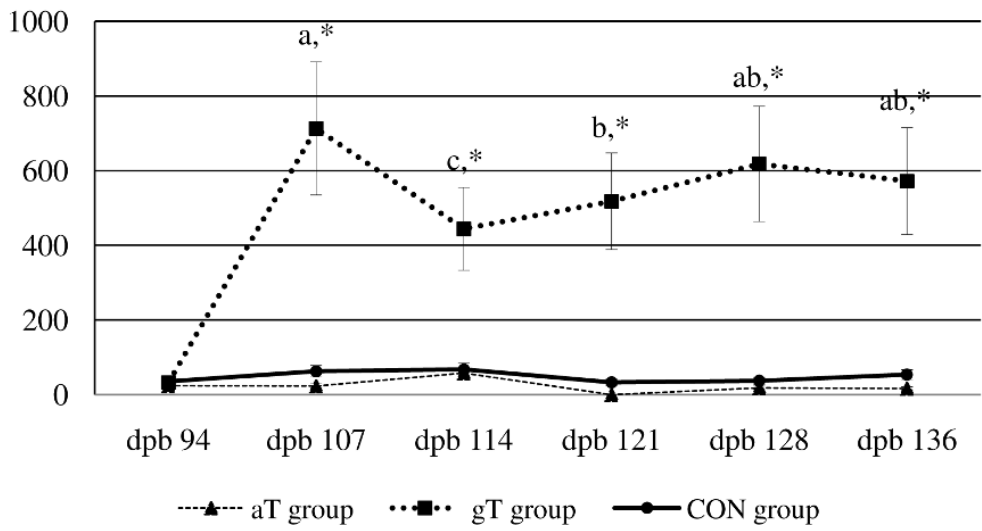

Figure 4 Serum tocopherol concentrations in late pregnant ewes supplemented with alpha tocopherol, gamma tocopherol or placebo. a. Serum alpha tocopherol concentrations $(\mathrm{mg} / \mathrm{kg})$ during late pregnancy in supplemented ewes. Line graphs represent median $\left(25^{\text {th }}, 75^{\text {th }}\right.$ percentile); *- aT group significantly different from gT and CON group $(\mathrm{P}<0.001)$; ab - Median values with different superscripts were significantly different between days post breeding within aT group $(\mathrm{P}<0.05)$; No differences between days post breeding were observed for $\mathrm{g} T$ and CON groups; Bar - $25^{\text {th }}$ and $75^{\text {th }}$ percentile; dpb - days post breeding; aT - alpha tocoperhol; gT - gamma tocopherol; CON - placebo; b. Serum gamma tocopherol concentration $(\mu \mathrm{g} / \mathrm{kg})$ during late pregnancy in supplemented ewes. Line graphs represent median $\left(25^{\text {th }}, 75^{\text {th }}\right.$ percentile); *- gT group significantly different from aT and CON group $(P<0.001)$; Median values with different letters were significantly different between days post breeding within gT group $(P<0.05)$; No differences between days post breeding were observed for gT and CON groups; Bar - $25^{\text {th }}$ and $75^{\text {th }}$ percentile; dpb - days post breeding; aT - alpha tocoperhol; gT - gamma tocopherol; CON - placebo.

and placental concentrations of tocopherols, angiogenesis gene (VEGF, PIGF, eNOS and HIFs) mRNA expressions, and morphometry of placental vascular network following daily oral supplementation in late pregnant ewes. The findings of this study indicated that oral supplementation of tocopherols to pregnant ewes during late gestation increased their serum concentrations; increased their concentrations in uterine and placentomal tissue; alpha tocopherol increased mRNA expression of PlGF, eNOS and HIF-1 $\alpha$ in cotyledon compared to placebo; gamma tocopherol increased VEGF and eNOS mRNA expressions in caruncle and uterus, and HIF- $1 \alpha$ in cotyledon, HIF- $1 \alpha$ and HIF- $2 \alpha$ in caruncle and uterus compared to placebo; morphometry analysis of angiogenic parameters favored increased angiogenesis. 


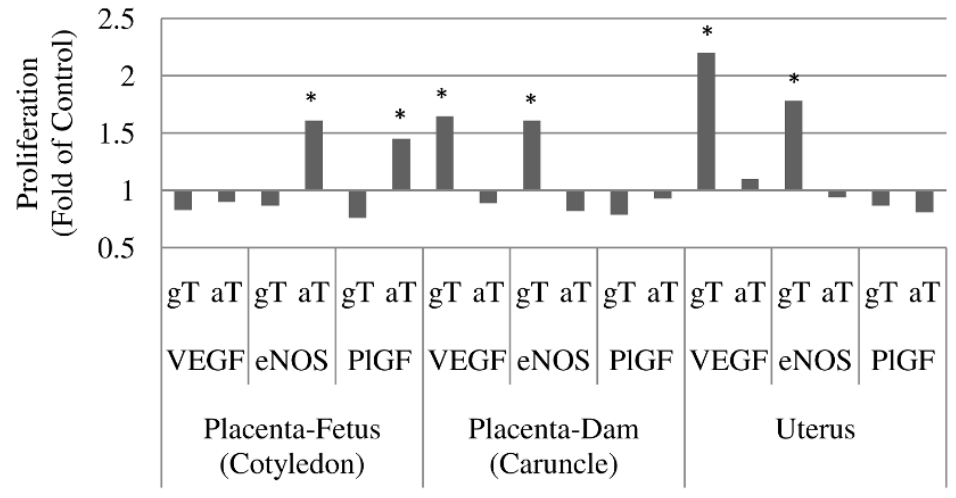

b

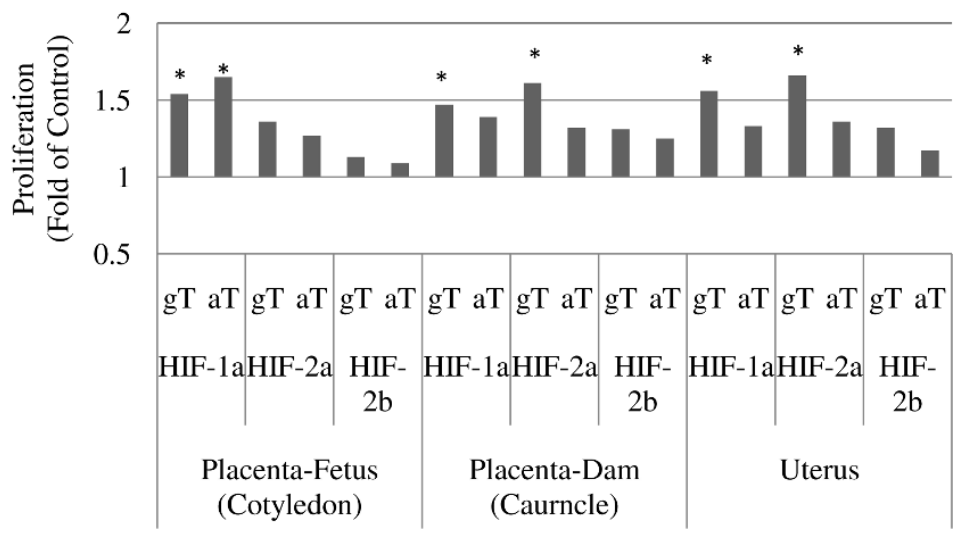

Figure 5 Relative mRNA of target genes expressed in uterus and placenta of late pregnant ewes following oral supplementation of alpha tocopherol, gamma tocopherol or placebo. a. Vascular endothelial growth factor, endothelial nitric oxide synthase, and placental growth factor mRNA expression in placenta and uterus following alpha or gamma tocopherol oral supplementation ( $x$ expression relative to control $=1$; * $\mathrm{P}<0.05$ ); b. Hypoxia inducible factors (HIF- $1 \alpha$, HIF-2 $\alpha$, HIF-2 $\beta$ ) expression in placenta and uterus following alpha or gamma tocopherol oral supplementation ( $\times$ expression relative to control $=1 ;{ }^{*} \mathrm{P}<0.05$ ).

In this study, the serum and tissue level of aT $(\mathrm{mg} / \mathrm{kg})$ was higher than $\mathrm{gT}(\mu \mathrm{g} / \mathrm{kg})$ even with increased gT daily dose. Gamma-tocopherol is initially absorbed in the same manner as alpha-tocopherol following administration, however, only small amounts of gamma-tocopherol are detectable in blood and tissue [32]. The bioavailability of aT is 5 to 10 times more than gT, could explain the reason for lower serum and tissue gT [33,34]. Other factors that could be responsible include high fat intake [35], oxidative stress [36,37], dose and half-life [38], species and cell type in question, and the chemical vitamer. The d2-gamma-tocopherol half-life was $13 \pm 4 \mathrm{~h}$ compared with $57 \pm 19 \mathrm{~h}$ for $\mathrm{d} 6$-alpha-tocopherol [38]. Considering the half-life, the daily oral supplementation and biweekly serum sample collection in this study occurred in the mornings, between 0800 and $0900 \mathrm{~h}$, and could also be the possible explanation for the lower gamma tocopherol levels in the serum. Also, it has been demonstrated that aT transfer protein is present in early and late term placenta in other species [39]. Hence it is possiblethat aT was better able to transfer across to the cotyledon and thereby increased tissue aT concentration. 


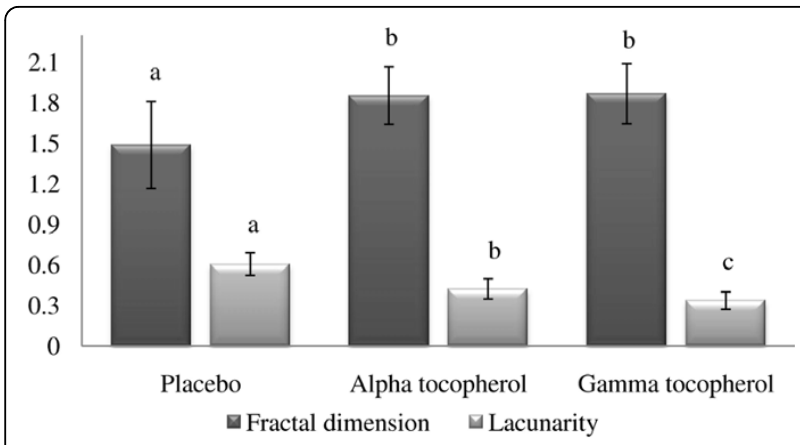

Figure 6 Fractal dimension and lacunarity of placental vascular network of late pregnant ewes supplemented with alpha tocopherol, gamma tocopherol or placebo. Bar graph represents expression of fractal dimension and lacunarity of treated groups. Groups with different letters were significant $(P<0.05)$.

Tocopherols exhibit complex biological effects reflecting their diverse nutritional, antioxidant and signaling properties [26]. The biologically active range of tocopherols is relatively narrow ( 3-4-fold variation). Because of this relatively narrow "window of efficacy," benefits from tocopherols might require continuous consumption to be effective. Once ingested, orally administered vitamin $\mathrm{E}$ plateaus in the plasma by $24 \mathrm{~h}$ but does not fully distribute to all biological compartments until at least $\sim 1$ week after ingestion [27]. It is consistent in this study that the serum concentrations of both aT and gT spiked during the first week and maintained at increased levels during rest of the study.

Several factors including VEGF, PIGF, basic Fibroblast Growth Factor (bFGF), epidermal growth factor, eNOS and angiopoietins 1 and 2 have been recognized as important regulators of placental development [2,40,41]. In the present study, alpha tocopherol increased mRNA expression of PIGF in cotyledon compared to placebo, and gamma tocopherol increased VEGF in caruncle and uterus. In ewes, maternal placental vascularization is dependent upon VEGF and angiopoietins expression. In contrast, fetal placental vascularization depends on numerous angiogenic factors [42,43]. It has been demonstrated that both VEGF and PIGF driven angiogenesis acts via an eNOS activated, nitric oxide mediated pathway [44]. In this study, aT increased the eNOS in cotyledon and gT increased the eNOS in caruncle and uterus. In pioneering studies, Cooney et al $[14,45]$ showed that tocopherol reduces nitrogen dioxide to the less harmful nitric oxide. Because endothelium derived nitric oxide is a key regulator of vascular homeostasis, up-regulation of endothelial nitric oxide synthase and nitric oxide formation by tocopherol could be important in promoting angiogenesis [46].

In this study aT, increased mRNA expression of HIF$1 \alpha$ in cotyledon compared to placebo. The gT increased
mRNA expressions of HIF- $1 \alpha$ in cotyledon, and HIF- $1 \alpha$ and HIF-2 $\alpha$ in caruncle and uterus compared to placebo. Hypoxia-inducible factor is the main regulator of the cellular response to low oxygen levels in mammalian species, playing a key role in regulating many physiological functions. The 2 principal HIF- $\alpha$ subunits, HIF- $1 \alpha$, which is ubiquitously expressed and HIF-2 $\alpha$, which shows a spatially restricted expression, both play important roles in vascular development and endothelial function [47-49]. Hypoxia inducible factor- $1 \alpha$ or HIF- $2 \alpha$ combine with HIF-1 $\beta$ to form the functional basic helixloop-helix transcription factor HIF-1 to stimulate transcription of the VEGF gene via interaction with the hypoxia response element (HRE) [25]. This occurs under hypoxic conditions, but is down regulated under normoxic conditions due to targeted proteolysis of HIF$1 \alpha$ and HIF- $2 \alpha$, mediated by the von Hippel-Lindau tumor suppressor gene product (pVHL). Additionally, VEGF is regulated post-transcriptionally through stabilization of its mRNA by interaction with heterogeneous nuclear ribonuceloprotein L (hnRNP L). The basic helix-loop-helix transcription factor HIF- $2 \alpha$ is also capable of heterodimerizing with HIF- $1 \alpha$ to form functional HIF-1. Several genes encoding growth factors and tyrosine kinase receptors essential for endothelial cell growth and function such as EPO, VEGF, eNOS and Flk-1 were shown to contain HIF-binding sites in their promoter/enhancer sequences.

Although placental and fetal growth and development are driven by the program encoded in its genome, the genetic regulation is influenced by the intra-uterine environment in which the fetus grows. The size and nutrient transfer capacity of the placenta plays a central role in determining the prenatal growth trajectory of the fetus. Angiogenesis is the process of formation of new vessels from preexisting vessels. Although tissue hypoxia is the main drive for angiogenesis, a growing body of evidence has demonstrated that oxidative stress can also be a potent trigger for the development of new vessels. Hence it seems reasonable that the presence of no or high oxidative stress may result in formation of new vessels. Angiogenic sprouting is controlled by the balance between pro-angiogenic signals (VEGF) and factors that promote quiescence (pericyte) or VEGF inhibitors [50]. In conditions that favor angiogenesis, some endothelial cells can sprout, whereas others fail to respond. In the present study, morphometric analysis revealed ewes supplemented with alpha- or gamma-tocopherol had increased fractal dimension and decreased lacunarity compared to placebo treated ewes indicated increased angiogenesis in utero-placental vascular network. It should be noted that even though not significant reduced mRNA expressions for VEGF, PlGF and eNOS in uterus and placenta were observed in this study. 


\section{Conclusions}

This study evaluated cellular responses to supplementation in order to understand the mechanisms behind the biological effects of tocopherols on placental angiogenesis during late gestation in pregnant ewes. The tocopherol concentrations of uterus and placentome increased following oral supplementation. In aT supplemented ewes, mRNA expression of PlGF, eNOS and HIF- $1 \alpha$ in cotyledon were greater than the CON group. In gT supplemented ewes, VEGF and eNOS mRNA expressions in caruncle and uterus, and HIF- $1 \alpha$ in cotyledon, HIF- $1 \alpha$ and HIF- $2 \alpha$ in caruncle and uterus were greater than the CON group. Morphometry analysis revealed angiogenic parameters favoring increased angiogenesis. Given the findings, it is plausible that the angiogenesis observed in this study might be a prooxidant and proangiogenesis pathway. Based on the results observed in this study we confer that the tocopherols supplementation can be employed to promote placental angiogenesis during late gestation. The oral tocopherol supplementation may be considered as an option to overcome pregnancy complications due to placental ischemia during late gestation.

\section{Additional material}

Additional file 1: Supplemental Table S1: Composition of hay fed free choice to the pregnant ewes during the trial period Additional file 2: Supplemental Table S2: Average tocopherols content in supplements.

Additional file 3: Supplemental Table S3: ' $P$ ' values for the effect of treatment and stage of gestation on serum concentration of alpha and gamma tocopherol in ewes $(\mathrm{N}=18)$ supplemented with tocopherols.

Additional File 4: Supplemental Table S4: ' $P$ ' values for the comparison of differences in the serum alpha and gamma tocopherol concentrations during different stages of gestation in ewes $(\mathrm{N}=18)$ supplemented with tocopherols.

\section{Acknowledgements}

This study was funded by College of Veterinary Medicine, Washington State University, Pullman WA 99164 and by Virginia-Maryland Regional College of Veterinary Medicine, Blacksburg, VA 24061. The authors acknowledge Geraldine Magnin-Bissel and Jonathan Dohanich, Virginia-Maryland Regional College of Veterinary Medicine, Blacksburg, VA 24061 for the technical support.

\section{Author details}

${ }^{1}$ College of Veterinary Medicine, Washington State University, Pullman, WA 99164, USA. ${ }^{2}$ Virginia-Maryland Regional College of Veterinary Medicine, Virginia Polytechnic Institute and State University, Blacksburg, VA 24061, USA. ${ }^{3}$ College of Nursing and Health Innovation, Arizona State University, Phoenix, AZ 85004, USA.

\section{Authors' contributions}

RK did the work of acquisition of funding, conception, design and collection of data, morphometry analysis, data analysis and interpretation, and drafting of the manuscript, tables and figures. VK contributed the design and conception, PCR analysis, collection of data and drafted the manuscript. JR contributed to the work of morphometry analyses. KDP did the work of feed supplementation, euthanasia, and collection of samples. PDS contributed to the work of postmortem tissue sample collection and histology. CDT contributed to the work of HPLC, and revised the manuscript for content and language. All authors read and approved final manuscript.

\section{Competing interests}

The authors declare that they have no competing interests.

Received: 23 November 2009 Accepted: 12 July 2010

Published: 12 July 2010

\section{References}

1. Folkman J, Klagsbrun M: Angiogenic factors. Science 1987, 235:442-447.

2. Sherer DM, Abulafia O: Angiogenesis during implantation, and placental and early embryonic development. Placenta 2001, 22:1-13.

3. Gruber M, Simon MC: Hypoxia-inducible factors, hypoxia, and tumor angiogenesis. Curr Opin Hematol 2006, 13:169-174.

4. Teicher BA: Hypoxia, tumor endothelium, and targets for therapy. Adv Exp Med Biol 2005, 566:31-38

5. Rojas A, Figueroa $H$, Re L, Morales MA: Oxidative stress at the vascular wall: Mechanistic and pharmacological aspects. Arch Med Res 2006, 37:436-448.

6. Sauer $\mathrm{H}$, Wartenberg $\mathrm{M}$ : Reactive oxygen species as signaling molecules in cardiovascular differentiation of embryonic stem cells and tumor induced angiogenesis. Antioxid Redox Signal 2005, 7:1423-434.

7. Liu Y, Zhao H, Li H, Kalyanaraman B, Nicolosi AC, Gutterman DD: Mitochondrial sources of $\mathrm{H}_{2} \mathrm{O}_{2}$ generation play a key role in flowmediated dilation in human coronary resistance arteries. Circ Res 2003, 93:573-580.

8. Zafari AM, Ushio-Fukai M, Akers M, Yin Q, Shah A, Harrison DG, Taylor WR, Griendling KK: Role of NADH/NADPH oxidase derived $\mathrm{H}_{2} \mathrm{O}_{2}$ in angiotensin II-induced vascular hypertrophy. Hypertension 1998, 32:488-495.

9. Jones DP: Radical-free biology of oxidative stress. Am J Physiol Cell Physiol 2008, 295:C849-868.

10. Burton GJ, Hempstock J, Jauniaux E: Oxygen, early embryonic metabolism and radical mediated embryopathies. Reprod Biomed Online 2003, 6:84-96.

11. Wiznitzer A, Furman B, Mazor M, Reece EA: The role of prostanoids in the development of diabetic embryopathy. Sem Reprod Endocrinol 1999, 17:175-181.

12. Jauniaux E, Hempstock J, Greenwold N, Burton GJ: Trophoblastic oxidative stress in relation to temporal and regional differences in maternal placental blood flow in normal and abnormal early pregnancy. Am J Pathol 2003, 162:115-125.

13. Jauniaux E, Watson AL, Hempstock J, Bao Y-P, Skepper JN, Burton GJ: Onset of placental blood flow and trophoblastic oxidative stress: a possible factor in human early pregnancy failure. Am J Pathol 2000, 157:2111-122.

14. Traber MG, Burton GW, Hamilton RL: Vitamin E trafficking. Ann N Y Acad Sci 2004, 1031:1-12.

15. Williamson KS, Gabbita SP, Mou S, West M, Pye QN, Markesbery WR, Cooney RV, Grammas P, Reimann-Phillip U, Floyd RA, Hensley K: The nitration product 5-nitro-gamma-tocopherol is increased in the Alzheimer brain. Nitric Oxide 2002, 6:221-227.

16. Cooney RV, Franke AA, Harwood PJ, Hatch-Pigott V, Custer LJ, Mordan LJ: $\gamma$-Tocopherol detoxification of nitrogen dioxide: Superiority to $\alpha$-tocopherol. Proc Natl Acad Sci USA 1993, 90:1771-1775.

17. Saldeen T, Li D, Mehta JL: Differential effects of alpha- and gammatocopherol on low-density lipoprotein oxidation, superoxide activity, platelet aggregation and arterial thrombogenesis. J Am Coll Cardiol 1999, 34:1208-1215.

18. Burton GW, Traber MG: Vitamin E: antioxidant activity, biokinetics, and bioavailability. Ann Rev of Nutr 1990, 10:357-382.

19. Ozer NK, Sirikci O, Taha S, San T, Moser U, Azzi A: Effect of vitamin E and probucol on dietary cholesterol-induced atherosclerosis in rabbits. Free Radic Biol Med 1998, 24:226-233.

20. Keaney JF Jr, Gaziano JM, Xu A, Frei B, Curran-Celentano J, Shwaery GT, Loscalzo J, Vita JA: Low-dose $\alpha$-tocopherol improves and high-dose $\alpha$-tocopherol worsens endothelial vasodilator function in cholesterolfed rabbits. J Clin Invest 1994, 93:844-851. 
21. Kontush A, Finckh B, Karten B, Kohlschutter A, Beisiegel U: Antioxidant and prooxidant activity of $\alpha$-tocopherol in human plasma and low density lipoprotein. J Lipid Res 1996, 37:1436-1448.

22. Versari D, Daghini E, Rodriguez-Porcel M, Sattler K, Galili O, Pilarczyk K, Napoli C, Lerman LO, Lerman A: Chronic antioxidant supplementation impairs coronary endothelial function and myocardial perfusion in normal pigs. Hypertension 2006, 47:475-481.

23. Shibata A, Nakagawa K, Sookwong P, Tsuduki T, Oikawa S, Miyazawa T: $\delta$-Tocotrienol suppresses VEGF induced angiogenesis whereas r-tocopherol does not. J Agri Food Chem 2009, 57:8696-8704.

24. Hewitt DP, Mark PJ, Waddell BJ: Glucocorticoids prevent the normal increase in placental vascularity during late pregnancy in the rat. Endocrinology 2006, 147:5568-5574.

25. Regnaulta TRH, Galanb HL, Parkera TA, Anthony RV: Placental development in normal and compromised pregnancies-A review. Placenta 2002, 23 S119-129.

26. Panfili G, Fratianni A, Irano M: Normal phase High-Performance Liquid Chromatography method for the determination of tocopherols and tocotrienols in Cereals. J Agric Food Chem 2003, 51:3940-3944.

27. Katsanidis E, Addis PB: Novel HPLC analysis of tocopherols, tocotrienols, and cholesterol in tissue. Free Radic Biol Med 1999, 27:1137-1140.

28. Tsatsaris V, Goffin F, Munaut C, Brichant JF, Pignon MR, Noel A, Schaaps JP, Cabrol D, Frankenne F, Foidart JM: Overexpression of the soluble vascular endothelial growth factor receptor in preeclamptic patients: pathophysiological consequences. I Clin Endocrinol Metab 2003, 88:5555-5563.

29. Livak KJ, Schmittgen TD: Analysis of relative gene expression data using real-time quantitative PCR and the 2(-Delta Delta C(T)) Method. Methods 2001, 25:402-408.

30. Doukas CN, Maglogiannis I, Chatziioannou AA: Computer supported angiogensis quantification using image analysis and statistical averaging. IEEE Transact Informat Tech Biomed 2008, 12:650-657.

31. Talavera-Adame $D$, Xiong $Y$, Zhoa T, Arias AE, Sierra-Honigmann MR, Farkas DL: Quantitative and morphometric evaluation of the angiogenic effects of leptin. J Biomed Optics 2008, 13:064017, 1-7.

32. Traber MG, Elsner A, Brigelius-Flohe R: Synthetic as compared with natural vitamin $\mathrm{E}$ is preferentially excreted as alpha-CEHC in human urine: studies using deuterated alpha-tocopheryl acetates. FEBS Lett 1998, 437:145-148

33. Lodge JK, Hall WL, Jeanes YM, Proteggente AR: Physiological factors influencing vitamin E biokinetics. Ann N Y Acad Sci 2004, 1031:60-73.

34. Behrens WA, Madère R: Alpha- and gamma tocopherol concentrations in human serum. J Am Coll Nutr 1986, 5:91-106.

35. Bates CJ, Mishra GD, Prentice A: Gamma-tocopherol as a possible marker for nutrition-related risk: results from four National Diet and Nutrition Surveys in Britain. Br J Nutr 2004, 92:137-150.

36. Ferrari L, Herber R, Batt AM, Siest G: Differential effects of human recombinant interleukin-1 beta and dexamethasone on hepatic drug metabolizing enzymes in male and female rats. Biochem Pharmacol 1993, 45:2269-2277.

37. Shedlofsky SI, Israel BC, MCClain CJ, Hill DB, Blouin RA: Endotoxin administration to humans inhibits hepatic cytochrome P450-mediated drug metabolism. J Clin Invest 1994, 94:2209-2214.

38. Leonard SW, Paterson E, Atkinson JK, Ramakrishnan R, Cross CE, Traber MG: Studies in humans using deuterium-labeled alpha- and gammatocopherols demonstrate faster plasma gamma-tocopherol disappearance and greater gamma-metabolite production. Free Radic Biol Med 2005, 38:857-866.

39. Traber MG, Burton GW, Hughes L, Ingold KU, Hidaka H, Malloy M, Kane J, Hyams J, Kayden HJ: Discrimination between forms of vitamin E by humans with and without genetic abnormalities of lipoprotein metabolism. J Lipid Res 1992, 33:1171-182.

40. Zygmunt M, Herr F, Munstedt K, Lang U, Liang OD: Angiogenesis and vasculogenesis in pregnancy. Eur J Obstet Gynecol Reprod Biol 2003, 110: S10-S18.

41. Folkman J: Angiogenesis in cancer, vascular, rheumatoid and other disease. Nat Med 1995, 1:27-31

42. Reynolds LP, Borowicz PP, Vonnahme KA, Johnson ML, Grazul-Bilska AT, Redmer DA, Caton JS: Placental angiogenesis in sheep models of compromised pregnancy. J Physiol 2005, 15:43-58.
43. Borowicz PP, Arnold DR, Johnson ML, Grazul-Bilska AT, Redmer DA, Reynolds LP: Placental growth throughout the last two thirds of pregnancy in sheep: vascular development and angiogenic factor expression. Biol Reprod 2007, 76:259-267.

44. Ahmad S, Hewett PW, Wang P, Al-Ani B, Cudmore M, Fujisawa T, Haigh JJ, le Noble F, Wang L, Mukhopadhyay D, Ahmed A: Direct evidence for endothelial vascular endothelial growth factor receptor-1 function in nitric oxide-mediated angiogenesis. Circ Res 2006, 99:715-722.

45. Cooney RV, Harwood PJ, Franke AA, Narala K, Sundstorm AK, Berggren PO, Mordan L: Products of gamma-tocopherol reaction with NO2 and their formation in rat insulinoma (RINm5F) cells. Free Radic Biol Med 1995, 19:259-269.

46. Carr A, Frei B: The role of natural antioxidants in preserving the biological activity of endothelium-derived nitric oxide. Free Radic Biol Med 2000, 28:1806-1814.

47. Semenza GL: Regulation of mammalian $\mathrm{O}_{2}$ homeostasis by hypoxiainducible factor 1. Annu Rev Cell Dev Biol 1999, 15:551-578.

48. Jain S, Maltepe E, Lu MM, Simon C, Bradfield CA: Expression of ARNT, ARNT2, HIF1 alpha, HIF2 alpha and Ah receptor mRNAs in the developing mouse. Mech Dev 1998, 73:117-123.

49. Covello KL, Kehler J, Yu H, Gordan JD, Arsham AM, Hu C, Labosky PA, Simon MC, Keith B: HIF-2alpha regulates Oct-4: effects of hypoxia on stem cell function, embryonic development, and tumor growth. Genes Dev 2006, 20:557-570.

50. Gerhardt $H$, Golding M, Fruttiger M, Ruhrberg C, Lundkvist A, Abramsson A, Jeltsch M, Mitchell C, Alitalo K, Shima D, Betsholtz C: VEGF guides angiogenic sprouting utilizing endothelial tip cell filopodia. J Cell Biol 2003, 161:1163-1177.

doi:10.1186/1477-7827-8-86

Cite this article as: Kasimanickam et al: Tocopherol induced angiogenesis in placental vascular network in late pregnant ewes. Reproductive Biology and Endocrinology 2010 8:86.

\section{Submit your next manuscript to BioMed Central and take full advantage of:}

- Convenient online submission

- Thorough peer review

- No space constraints or color figure charges

- Immediate publication on acceptance

- Inclusion in PubMed, CAS, Scopus and Google Scholar

- Research which is freely available for redistribution

Submit your manuscript at www.biomedcentral.com/submit
C Biomed Central 